\title{
A lição de Alice: maravilhas da linguagem
}

\author{
Alice`s lesson: language wonders
}

\section{Maria Antónia Jardim}

Universidade Fernando Pessoa - UFP - Porto - Portugal

\begin{abstract}
$\longrightarrow$
Resumo: Este artigo pretende ser um contributo para a fundamentação psicopedagógica da criatividade através da narrativa de L. Carroll que permite ao leitor reordenar as significações e transformar imagens. A psicologia da arte triangula 0 sentimento e a imaginação enquanto ciência da subjectividade que é; que analisa e interpreta a realidade do ser humano como expressão versus informação.
\end{abstract}

Palavras-chave: Arte. Linguagem. Psicologia. Subjectividade.

Abstract: This paper is intended as a contribution to the foundation of the psychopedagogic creativity by L. Carroll 's narrative that allows the reader to reorder meanings and transform them into images. The Psychology of Art triangulates feeling and imagination as a science of subjectivity which analyzes and interprets the reality of the human being as an expression versus information.

Keywords: Art. Language. Subjectivity. Psychology 
O futuro do Homem é viver num universo colectivo de inteligências comunicantes onde não haverá nem mestres que ensinem, nem discípulos que aprendam. Todos aprenderão com todos.

Daniel Serrão in Procurar a Sabedoria, Partilhar o Conhecimento, 2010.

Sabemos que a linguagem da arte é ilimitada. É a linguagem das formas que comunicam. A arte é expressiva, não é descritiva. Ela exprime a perplexidade do ser humano diante da vida e do mundo, podendo manifestar a experiência universal da consciência humana. Por isso é que apontamos para a Psicologia do século $X X I$, um trilho até as enormes reservas intuitivas e humanísticas da arte.

Assim como esteve presente nas cavernas, acompanhará a humanidade até à última plataforma no espaço como testemunha do seu ser e estar no mundo.

Quem é o homem contemporâneo? O homem que se exprime através de mitos, narrativas, símbolos?

Para o filósofo, o símbolo manifestará a ligação do homem com o todo, do particular com o universal. A tese de Ricoeur é que a ambiguidade do símbolo, longe de ser uma deficiência e uma falta, é, de facto, a sua capacidade de suportar e engendrar interpretações adversas, mas coerentes, cada uma em si mesma.

Este é o nível propriamente hermenêutico, o nível das interpretações contraditórias. O que se constata é que o símbolo como objecto de estudo da hermenêutica exprime ambiguidade, o múltiplo, o híbrido e o diverso. E é esta multiplicidade e diversidade que falam da própria natureza múltipla e diversa da vida e do ser humano; da alteridade da própria identidade.

É da hermenêutica dos símbolos que passamos à hermenêutica de textos e da linguagem em geral, matéria prima da arte.

Um texto afigura-se-nos como um feixe de interpretações, no qual tanto 0 autor como o intérprete dialogam consigo mesmos. Relembremos que Ricoeur (1983) formula como chave de toda a hermenêutica o facto de o Homem ser a única "coisa" capaz de ser tocada pela Palavra. Assim, a hermenêutica exerce-se na materialidade da linguagem, que é, por sua vez, um verdadeiro fio condutor de um novo modo de pensar; quer dizer que, para a filosofia hermenêutica, o texto enquanto obra, testemunho do estar no mundo, permite-nos ver o mundo com outros olhos, abrimo-nos a outras perspectivas. O mundo já configurado pelo texto configura-nos, recria-nos, suspendendo o nosso olhar particular. O sujeito que lê e que interpreta os textos, testemunhos de vida já vivida e interpretada, é um sujeito aberto a outras perspectivas, com as quais até pode estar em conflito.

Os textos literários são textos que falam de qualquer coisa, que são a propósito de "um mundo": o mundo "é o conjunto das referências abertas pelos textos" (RICOEUR, 1975, p. 386). Por isso, a significação de um texto não é algo de escondido, mas de "descoberto- aberto"; o que se deixa compreender é o que, num texto, aponta para um mundo possível: "A interpretação torna-se, assim, a apreensão das proposições de mundo abertas pelas referências não ostensivas do texto"; daí que compreender é ir do que a obra nos diz, (sentido), àquilo "a propósito de que" ela diz. Compreender interpretando e interpretar compreendendo é deixarse orientar por um horizonte, pelo modo possível de estar no mundo, aberto e descoberto pelo texto para o intérprete. Será tudo isto que confere ao sujeito uma nova capacidade de se compreender a si mesmo.

É o encontro de horizontes, o do texto e o do leitor, o verdadeiro fio condutor, pois o sujeito que interpreta o texto é, por sua vez, por ele interpretado. A apropriação ou leitura implicada modifica o leitor, obriga-o a desapropriar-se de si e a receber do texto uma nova proposta.

Interpretar é decifrar um sentido que advém à consciência, não sendo por esta constituído. Esta interpretação, co-implicada no descentramento do Cogito, deixa-se guiar numa tríplice direcção: para trás (desejo biológico), para a frente (imaginação poética) e para cima (transcendência). A este horizonte trifacetado correspondem três domínios simbólicos, que simultaneamente se configuram como 
outras tantas fontes de sentido: os sonhos e fantasmas do inconsciente, as obras da cultura e as representações do sagrado. Pelas obras de cultura, através da analogia que interpela o sujeito e pela ficção, novas possibilidades de estar-no-mundo são indicadas à realidade quotidiana.

Note-se que para Ricoeur (1986), do mesmo modo que o mundo do texto só é real na medida em que é fictício, (imaginado pelo sujeito) é necessário dizer que a subjectividade do leitor só se produz a si mesma na medida em que é posta em suspenso. Tal facto tem a ver com o que Michel Meyer chama de "verosimilhança do inverosímil", pois, segundo este autor, o discurso ficcional pode produzir a ilusão mimética (verosimilhança); é que a distinção entre o que é real e o que é ficcional no interior do texto encontra-se confundida pelo efeito de crença, crescente com a leitura, no mundo do texto, de tal modo que, utilizando a linguagem, o narrador distorce a realidade e faz com que, por exemplo, um ser de fantasia ganhe voz. Por outras palavras, se a ficção é uma dimensão fundamental da referência do texto, ela não é menos uma dimensão fundamental da subjectividade do leitor. Assim sendo, podemos concluir que as histórias ajudarão os leitores a equacionarem os seus dilemas, os seus problemas e as suas perguntas e respostas relativas à sua vida, e por isso poderemos dizer que os sujeitos leitores se tornam objectos e experiência de linguagem de tal modo que, por vezes, as próprias personagens (é o caso da obra de Carroll) convencem o leitor da realidade que está a ser narrada.

Afigura-se-nos o emergir do universo ficcional no mundo real, que Umberto Eco abordou na obra Seis passeios no bosque da ficção (1995), onde afirma que, desde muito tempo os homens se questionam sobre a existência de uma mensagem e se essa mensagem faz sentido. Os universos ficcionais extinguem essas dúvidas e dúvidas e fazem emergir uma entidade autoral, identificada com o seu criador, juntamente com um conjunto de instruções de leitura que, acrescentaríamos, podem ajudar a construir "versões de mundo", segundo os conceitos de Goodman (1995).
Assim, poderemos concluir, indo de encontro às propostas de Nelson Goodman, que os factos são construídos tanto quanto o são as ficções e que estas podem ser informativas e formativas. Isto quer dizer que o mundo ficcional nos pode dar a ler informações acerca dos nossos comportamentos, na medida em que através dele podemos experimentar afinidades de olhares, encontros com atitudes de outros sujeitos.

A ficção é fascinante porque nos oferece a oportunidade de exercer livremente as nossas faculdades, quer para percebermos o mundo, quer para reconstruirmos o nosso passado.

A ficção é lúdica tal como as peças de Lego que nos permitem efectuar e estruturar diferentes experiências de construção, mas este facto pode conduzir-nos a uma ambiguidade; a uma textura híbrida no momento presente, como nos relembra Eco (1995). Porém, temos de convir que, se a actividade narrativa está estreitamente ligada à nossa vida quotidiana, poderá acontecer de interpretarmos a vida como ficção e introduzirmos elementos ficcionais quando interpretamos a realidade. Não é possível desligarmo-nos da "função adesiva" da memória, do modo como funcionamos, porque damos crédito ou não a histórias anteriores, a histórias da vida privada ou pública, até às histórias que a própria História nos narrou até hoje. Apoiamo-nos num contador $X$ e numa história $\mathrm{T}$ e fazemos rosários de memórias individuais e colectivas, tomando essas contas com a vida como promessas de imortalidade, que nos libertarão da lei da morte afirmando "e assim rezava a história".

A ficção transborda para a vida real como a origem ou resultado de uma acção transborda da Palavra (Platão, Crátilo), até que um dia a palavra ficção deixe de fazer sentido. De qualquer modo, continuamos no plano da interpretação de si, a qual, para Ricoeur, vai encontrar na própria narrativa, uma mediação privilegiada, até porque considerações éticas estão implicadas na própria estrutura do acto de narrar (RICOEUR, 1991). Para Ricoeur (1990), é a narrativa que constrói a identidade da personagem, que podemos chamar identidade narrativa; logo, será a identidade da história que faz a identidade da 
personagem e é exactamente neste ponto que o conceito de imaginação se torna pertinente.

A capacidade de imaginar permite uma flexibilidade que pode revigorar todas as funções mentais, tornando-se um instrumento vital em termos pedagógico-éticos, algo também sublinhado por Ricoeur em La Métaphore Vive, que aborda o conceito de leitura como sendo um acto com dois traços: um de "abertura" e outro de "suspensão", sendo esta abertura uma abertura ao imaginário. Para o filósofo, o "voir comme" seria um factor que se revela no acto de ler, o modo através do qual o imaginário emerge: Assim o "ver como" posto em cena a partir do ato de ler assegura a inter-relação entre o sentido verbal e a plenitude imaginária (RICOEUR, 1975). Ao lermos ou relermos histórias de vida diferentes da nossa, ainda que animadas por personagens, manifestam-se, em nós, leitores, interrogações, juízos de valor e comparações e perguntas em que o advérbio de comparação surge: Ele faz como eu? Então, em última instância, é a nossa maneira de ver a vida que está em causa. Por isso, e como sublinha Ricoeur (1991), a narração nunca é eticamente neutra, mostrando-se como o primeiro laboratório do julgamento moral. Trata-se de uma feliz imagem ricoeuriana, que nos permite perceber que o racional e o sensível se sobrepõem neste processo: o objectivo subjectiviza-se e o subjectivo objectiviza-se, na e pela linguagem. Deste modo, a arte literária afigura-se, por excelência, como palco laboratorial para experiências de pensamento onde variações imaginativas proliferam. São essas experiências de pensamento, suscitadas pela ficção, com todas as implicações éticas, que contribuem para o exame de si mesmo no quotidiano. Estética e ética tornam-se indissociáveis na arte de narrar, que é uma arte que corresponde a uma troca de experiências. Tanto assim, diz-nos Ricoeur, que, muitas vezes, o prazer que temos ao seguir o destino de uma personagem relaciona-se com o prazer em explorar novas maneiras de avaliar acções e personagens.

Logo, não é de estranhar que, por vezes, o interpretar do texto da acção coincida com a interpretação do agente que se interpreta a si próprio.
É deste modo que a nova figura de alteridade pode ser convocada, pois há um poder do texto sobre o leitor, como identifica Ricoeur (1991), já que o aparentemente estranho se torna familiar a meu semelhante ao afirmar "eu". Ricoeur descreve este processo como "transferência analógica", que podemos relacionar com o pacto narrativo descrito por Eco, tal com tradizido para o português (1995, p. 16)

Parece-me justo que, enquanto passeio num bosque, utilize cada experiência e cada descoberta para aprender a respeito da vida, a respeito do passado e do futuro. Mas como um bosque é criado para toda a gente, não devo procurar nele factos e sentimentos que só a mim dizem respeito.

Nesta metáfora florestal, os leitores podem deambular no próprio bosque ou serem induzidos a dar passeios imaginários num bosque irreal. De qualquer modo, poderão sempre escolher entre voltarem-se para a sua própria experiência de vida ou para o conhecimento que têm de outras histórias. Isto faz com que, de algum modo, Eco sugira que os mundos ficcionais sejam parasitas do mundo real, podendo, deste modo, surgir meta-realidades para o leitor. Todavia, existe uma dificuldade a que Ricoeur (1990) não é alheio, que é saber como as experiências de pensamento suscitadas pela ficção, com todas as implicações éticas, contribuíram para o exame de si mesmo na vida real? Como é que o julgamento moral é ele próprio submetido a variações imaginativas próprias da ficção? Mas é ele próprio que responde essa questão, afirmando que a interpretação é o processo pelo qual, no jogo da pergunta e da resposta, os interlocutores determinam em comum os valores contextuais que estruturam seu diálogo.

De qualquer modo, a questão da identidade/alteridade do Si mesmo como um outro conduz-nos a uma outra questão não menos importante: a mimesis e o "ser à imagem de". Além de ser um conceito bastante trabalhado em Ricoeur, que retomaremos mais tarde, é interessante observarmos desde já a perspectiva de Jean-Jacques Wunemburger, que propõe que a imagem tem que ver com a representação, com a experiência do 
duplo, conduzindo-nos a pensar numa natureza dupla, contraditória, feita de combinações paradoxais do mesmo e do Outro. Note-se que Ricoeur diz-nos, em Temps et Récit I, que é preciso entender mimesis (III) como "imitação" ou "representação dinâmica"; observe-se que a poética mimética carrega consigo uma imaginação ficcional que permite reconfigurar o real, potenciar a imagem com toda a sua carga simbólica e energia transformadora; como afirma Wunemburger na sua obra já citada, que a imagem exibe, no fundo de si mesma, um dos múltiplos rostos do Homem.

É, enfim, a questão do desdobramento do Simesmo como um Outro a questão da alteridade que cada um de nós transporta consigo, no seu cogito sonhador, nas suas estruturas antropológicas do imaginário, num "mundus imaginalis" que atravessa um paradigma genealógico, pois, se por um lado, a imaginação é uma figuração do sentido, por actos de correspondência, então, uma interpretação, uma hermenêutica deste sentido, assim como a reconstrução dos actos que levaram à sua elaboração, deve ser um instrumental de uma pedagogia do imaginário e de uma psicologia da arte.

Isto leva-nos ao apelo de Durand, na sua obra L'Imagination Symbolique (1995) quando defende uma introdução às "hermenêuticas instauradoras", que reflectem sobre a linguagem simbólica do imaginário e se apercebem, por isso, da sua semântica, na linha de Jung, Cassirer, Bachelard e de Ricoeur. Durand eleva o imaginário à linguagem, por excelência susceptível de nos revelar a nós próprios, pois quer na literatura, na arte, na mitologia, quer na religião, manifesta-se uma "imaginação semântica" e "uma hermenêutica imaginativa". Ricoeur afirma que

[...] variações imaginativas, jogo, metamorfose - todas estas expressões tentam limitar um fenómeno fundamental, a saber, que é na imaginação, que em primeiro lugar, se forma em mim o ser novo. Afirmamos, de facto, a imaginação e não a vontade. Porque o poder de se deixar apreender por novas possibilidades precede o poder de se decidir e de escolher. (RICOEUR, 1956, p. 137)
Para o nosso filósofo, em última instância, é à nossa imaginação que o texto se dirige; é ela o seu destinatário.

É necessário compreender que a imaginação é uma aventura no campo da percepção (BACHELARD, 1957) e ter em conta que, assim como o autor-narrador-sonhador fala ao mundo, também esse mesmo mundo vai fazer o sujeito leitor-coautor entrar numa aventura de bem-estar, de correspondências, e por último, de metamorfoses; o mundo do texto fica contaminado pelo nosso olhar.

Ainda relembrando Ricoeur, 0 discurso projecta um ser e estar-no-mundo onde nós sujeitos leitores, coautores, podemos ser e estar de muitas maneiras, inclusive cruzando a nossa alteridade com a alteridade que o próprio texto proporciona, através do método hermenêutico.

Será, então, esta possibilidade infinita de ser e estar-no-mundo que há que promover junto dos seres humanos; que há que rever como tarefa hermenêutico-ética, onde a imaginação tem o seu lugar como pedagogia da alteridade. Um ser e estarno-mundo em que identidade pessoal e identidade narrativa se tornam interactivas.

Apontamos para o ser humano em contexto, como ser histórico que é, pertencendo a um sistema social e cultural determinado. Mas, se a compreensão do indivíduo como ser histórico é de fundamental importância para uma redefinição no campo de estudo da psicologia, a compreensão do sujeito enquanto ser subjectivo, expressivo e, portanto, narrativo não se tornam menos significativas.

Ricoeur e Vygotsky complementam-se na medida em que não se concebe uma construção individual sem a participação do Outro (vide Soimême comme un Autre), e do meio social, o que torna imprescindível a relação intersubjectiva, já que é nesse espaço relacional e dialógico que existe a possibilidade do conhecimento e da partilha dos saberes.

Deste modo, apenas o ser humano pode educar o ser humano (VYGOTSKY, 2003). O acto de educar é um acto relacional; mas, se a educação é um acto dialógico, a educação através da arte é um 
acto vivencial. Tal tem que ver com a perspectiva Vygotskiana de que a vida humana é um trabalho criativo e que a pessoa transformada nesse processo criativo atinge novos níveis de insight e de compreensão. Utilizando a linguagem vygotskiana, cada obra de arte é uma janela de aprendizagem para o sujeito psicológico, um espelho onde a imagem se renova ou se retrata... relembrando Greimas, um "espaço tópico" que permite ao sujeito uma transformação, uma metamorfose (ex: a obra Alice no país das maravilhas).

Não nos esqueçamos de que, segundo Vygotsky (2009), a criança aprende primeiro a compreender os outros e só depois, seguindo o mesmo modelo, aprende a compreender-se a si mesmo; uma ideia que é sublinhada por Ricoeur na sua obra $O$ si mesmo como um outro.

Por um lado, Vygotsky dá ênfase à educação dos sentimentos, pois, se quisermos que os alunos recordem melhor ou exercitem mais o pensamento, deveremos fazer com que as actividades sejam emocionalmente estimuladas; por outro lado, para este autor, a emoção não é uma ferramenta menos importante que o pensamento. É aqui que vemos o papel fundamental da Psicologia da Arte enquanto sensibilização para o mundo sensível da Beleza e do afecto objectivado na vivência experimental; enquanto promotora do duplo referencial cognitivo/afectivo.

A Psicologia da Arte ajuda a compreender a matéria dos sonhos e a própria cultura como metamorfose hermenêutica.

Atente-se, pois, na evidência de que somos sujeitos, ocupando um determinado lugar/espaço no mundo, situados, pois, na acção, num tempo, com um determinado modo de agir e pensar, isto é, de comunicar com o que está à nossa volta, com uma memória (tempo da narrativa = passado), fazendo história, construindo peripécias... tal como uma personagem de um conto. No fundo, somos seres feitos de linguagem, fazemos escolhas, até com os pronomes (possessivos, demonstrativos, indefinidos) e com o modo dos verbos (conjuntivo, imperativo), e com os adjectivos e advérbios que utilizamos. Todos os dias, cruzamos a sintaxe do discurso com a sintaxe da vida. É esta consciência da tridimensionalidade da linguagem que o aluno de Psicologia da Arte deve ter.

O tempo "nasce", como diz Merleau-Ponty (1971), da relação da pessoa com as coisas. A memória é uma construção. Mais do que uma função mecânica de pura reprodução, a memória é uma função simbólica. Daí que a evocação não é a imagem, mas um juízo sobre a imagem no tempo. Ex: relembrar a Mona Lisa é avaliá-la e associá-la na minha contemporaneidade...assim como lembrar de Alice é associar a imagem de Alice aos valores simbólicos; às maravilhas que ela representa e, mutatis mutandis, compará-la com os de hoje. É sob o signo da associação de ideias que se coloca essa espécie de curto-circuito entre memória e imaginação, se essas duas afecções estão ligadas por contiguidade, evocar uma delas - portanto, imaginar é evocar a outra - portanto lembrar-se. A memória como recordação opera, assim, na trilha da imaginação.

Desde já queremos introduzir este novo conceito e reforçar a ideia de que a interpretação de uma história/conto poderá ajudar numa autointerpretação, proporcionando novos horizontes/mundos para o aluno como leitor assim como novas experiências e descobertas (alteridade) para o aluno como coautor. Todo este processo conduzirá não mais a uma heteronímia (remetemos para o conceito pessoano) do ser humano, mas a um assumir de papéis, consciente, de uma alteridade que se conquista através de uma interpretação que vai de uma crítica ingênua a uma segunda crítica e não pelo acaso que um determinado contexto pode proporcionar. Daí que possamos dizer que, muito sucintamente, a Psicologia da Arte é um saber interpretar para melhor compreender e daí que uma autocompreensão se torne indissociável de sucessivas auto-interpretações, por sua vez possibilitadas por uma hermenêutica da narrativa. Desse modo, um leitor pode declarar reconhecer-se num determinado personagem e essa apropriação pode assumir uma variedade de formas, passando por estados de fascinação, suspeição, revolta, 
rejeição, sedução... Aprender a "narrar-se" poderá ser o benefício dessa apropriação crítica, sendo que tal pode acontecer numa narrativa visual, auditiva, gestual...sempre simbólica.

Assim, a Psicologia da Arte que pretende aprofundar o auto-conhecimento, que passa pelo crivo da norma, que promove a liberdade, tem de passar pelo confronto com o estranho, pois a Arte para além de levar à descoberta de conflitos, deverá igualmente permitir encontrar uma saída para os impasses e dilemas que a vida apresenta. Deste modo, em termos morais, ao promovermos a liberdade e esse confronto com o estranho, estaremos igualmente a promover a liberdade como auto-legislação, isto é, como autonomia criativa.

Todo o sujeito é singular, possui a sua história de vida, interesses particulares, e é através da linguagem que se irá exprimir, representar, o seu modo de ser e estar-no-mundo.

Indo ainda mais longe, e como conclui o psicólogo do desenvolvimento Vygotsky (1987), as palavras têm um papel central não só no desenvolvimento do pensamento, mas também na evolução histórica da consciência como um todo.

Observa-se, assim, o papel fundamental que a linguagem desempenha na constituição dos sujeitos e a importância da interacção verbal social no processo ensino-aprendizagem, que jamais é eticamente neutro. Mesmo quando o professor faz paráfrases, operação típica do discurso pedagógico e explica de outra forma, facilitando a compreensão por parte dos alunos, já aí o próprio professor fez uma hermenêutica, uma interpretação, que orienta para o sentido desejado, reflectindo e modificando uma determinada realidade. Quando num museu vemos os quadros legendados, ou numa exposição ao ar livre percebemos que as esculturas têm título... deparamo-nos com os mais variados Graffittis (ex: Muro de Berlim) ou ainda a obra prima de arquitectura da Bibliotheca Alexandrina envolta de hieróglifos, vamos lendo a intencionalidade dos autores.

Podemos, pois, concluir relativamente a este primeiro ponto, que a palavra, considerada produto ideológico, carrega em si lutas, conflitos e até mesmo o peso das determinações sociais que a produziram, razão pela qual o sentido da palavra ou do discurso, de forma mais ampla, somente poderá ser compreendido se se levar em conta tanto os sujeitos, quanto o contexto dialógico, o momento sóciohistórico e as formações social, ideológica e discursiva dos interlocutores.

Note-se que não há prática docente que não seja um ensaio ético-estético, pois a realidade é metamorfoseada por meio daquilo a que Ricoeur chama de variações imaginativas, através das quais a literatura opera sobre o real (RICOEUR, 1986), isto é, a função imaginativa articula-se com os valores que a realidade pode veicular, até porque, de uma perspectiva narrativa, nós somos histórias, biografias e, segundo Maclntyre (1981), autor com o qual Ricoeur debate o conceito de identidade narrativa, seremos apenas coautores das nossas próprias narrativas e, por conseguinte, somos de certeza coautores das histórias dos nossos contemporâneos.

Roland Barthes (1966) é de opinião que a história da narrativa começa com a história da humanidade, as guerras entre os homens são guerras de linguagem, a conquista do poder e do território começa com a palavra; o que leva a perguntarmo-nos se a utilização das abordagens hermenêuticas poderá ajudar as pessoas e seus respectivos dilemas, no seu quotidiano? A imaginação é a nossa ferramenta para engendrar metáforas, para dizermos as nossas histórias e assim redescrevermos quem somos, qual o nosso contexto e o que se torna significativo para nós, na nossa vida. As primeiras narrativas eram desenhos, pinturas rupestres, imagens toscas representando um mundo de sobrevivência humana. Mas como olharão os vindouros para os nossos livros encadernados ou para as nossas esculturas?

Note-se que é importante ter em conta que as próprias histórias contêm em si elementos de ordem prospectiva que nos podem ajudar a organizar o nosso futuro e, portanto, a questionar o presente. Daí que o sociólogo David Cooper proponha que os livros sejam diálogos em que o que se vai passando no livro se torne criação conjunta de todos nós, pois existe um tempo para as mentes, um tempo para abandonar 
as nossas mentes e um tempo para as recuperar. Em termos ricoeurianos, poderíamos dizer que há um tempo para nos apropriarmos da "coisa do texto" e um tempo para nos distanciarmos dela para reencontrarmos o nosso próprio sentido das coisas, no nosso contexto, já que escutar-se a si próprio é sempre uma condição prévia para ouvir a mensagem de outrem.

A arte literária promove, assim, uma imaginação moral!

A linguagem passa a ser assumida como o próprio fenómeno psicológico, como nos foi relembrando Vygotsky. Desde muito cedo que nós percebemos a realidade através da linguagem; daí que narrativa, neste contexto, seja definida como uma estrutura de significação que organiza os acontecimentos e acções humanas numa totalidade, atribuindo deste modo significado às acções e acontecimentos individuais de acordo com o seu efeito na totalidade. A narrativa surge, assim, não como uma representação de uma realidade cognitiva essencial, mas como um elemento central da experiência do indivíduo, uma forma de construir um conhecimento indissociável da experiência de existir.

O homem não se sente isolado no cosmos, está aberto para um mundo que, graças ao símbolo, se torna familiar. Por outro lado, e retomando a perspectiva ricoeuriana, as valências cosmológicas do simbolismo permitem-lhe sair da situação subjectiva e reconhecer a objectividade das suas experiências pessoais. Por outras palavras, quem compreende um símbolo não só se abre para o mundo objectivo como também consegue sair da sua situação particular e ter acesso à compreensão do universal.

Neste sentido, cabe ao verdadeiro artista ser um construtor de pontes, a arte enquanto linguagem deverá promover encontros significativos. Deste modo, a hermenêutica será a resposta do homem ocidental, talvez a única inteligente, afirma convicto Eliade, no Prefácio a Mefistófeles e o Andrógino (1991), às solicitações da história contemporânea, ao facto de o ocidente estar predestinado ao confronto com os valores culturais dos "outros". Este confronto com os "Outros" ajudará o homem ocidental ao autoconhecimento. O esforço para compreender os modos de pensamento estranhos à tradição racionalista ocidental; isto é, tentar decifrar a significação dos símbolos, traduz-se já num enriquecimento da consciência; traduz-se já num movimento dialéctico que vai da razão abstracta à razão sensível, que acompanha a tensão dos próprios símbolos.

Nos dias de hoje, os símbolos das crianças são as "Play stations", as PsPês, os vídeos, o computador...A narrativa é híbrida, uma mistura de imagens e palavras, de realidade e virtual. Com ela, surgem crianças também elas híbridas na medida em que as suas expressões simbólicas são ora muito sensíveis, ora muito racionais e encontrar o equilíbrio entre estas duas forças, a tal razão sensível, não é tarefa fácil. É neste contexto que surgem as denominadas crianças índigo (JARDIM, 2009).

A diminuição do distanciamento entre o pensar e agir. Por mais que todos saibam o que é certo e errado, frequentemente a maioria age de forma diferente. Acredita-se que essas crianças vão induzir e diminuir este distanciamento, gerando uma sociedade mais autêntica, transparente, verdadeira e confiante. Cabe à Psicologia da Arte chamar a atenção para o facto de que a Arte não é reflexão, mas vivência, contacto com a Beleza, com os valores, com as significações, até erro criativo, desvio.

É a mudança do fora do "eu" para o "próximo" que diminui ou elimina problemas como o egoísmo, a inveja, a exclusão e a agressão. É a Psicologia da Arte que vai permitir o desenvolvimento de uma atitude crítica e auto-crítica em termos de experiência ético-estética.

Será como passar através do espelho de Alice no País das Maravilhas, em educação. É um mundo surpreendente, algumas vezes desorientado, cheio de contos de fadas, mitos e lendas, ou música, arte, demonstração física, jogos e de livros de tarefas escritos e ilustrados por estudantes, um mundo sem exames, graus, computadores ou televisão.

É, em suma, um mundo onde as ideias e as práticas do sistema educativo ficaram para trás. Note- 
se que a energia de Índigo é uma energia que vai obrigar a uma ruptura com as antigas formas de ensinar. É uma energia que nos obriga a questionar as coisas, a mudar a forma como procedemos e até a forma de vivermos, com vista a uma alteração radical na expressão dos comportamentos humanos (JARDIM, 2009). Apontaremos, então, para um novo paradigma de educação em que o role playing é essencial da parte dos pais, educadores, professores...

$\mathrm{O}$ poder e o medo, o autoritarismo e a insegurança vão dar lugar ao Amor, ao respeito, à tolerância, sendo a Comunicação um dos meioschave com que se pode mostrar amor e respeito. $\mathrm{O}$ acto de comunicar é um acto de dar e receber. A pessoa que comunica está a dar e a partilhar ideias e a pessoa que ouve está a receber ideias. É deste brainstorming que nascem muitas vezes as obras de arte. Esta é a verdadeira comunhão de bens a que se refere Ricoeur quando fala de educação. É que o Outro, o índigo, funciona como janela de aprendizagem (Vygotsky) e espelho de auto e heteroconhecimento.

Será, pois, uma possibilidade infinita de ser- eestar-no-mundo que há que promover através da Psicologia da Arte, que há que rever como tarefa hermenêutico-ética, onde a imaginação tem o seu lugar como pedagogia da alteridade; em que o trabalho do escritor não é senão uma espécie de instrumento óptico que ele oferece ao leitor para que isso lhe permita discernir aquilo que sem o livro ele talvez não tivesse visto em si mesmo.

\section{Referências}

BARTHES, Roland. Critique et Vérité. Paris: Seuil, 1966.

BACHELARD, Gaston. La poétique de l'espace. Paris: Presses Univ. de France, 1957.

DURAND, Gilbert. A imaginação simbólica. Lisboa: Ed. 70, 1995.

ECO, Umberto. Seis passeios no bosque da ficção. Oeiras: Difel, 1995.

ELIADE, Mircea. Mefistófeles e o andrógino. Brasil: Martins Fontes, 1991.
GOODMAN, Nelson. Modos de fazer mundos. Porto: Asa, 1995.

JARDIM, Maria A. (Coord.) Crianças índigo: novas atitudes pedagógicas. Porto: Edições Universidade Fernando Pessoa, 2009.

MACINTYRE, Alasdair. After Virtue: a study in moral theory. London: Duckorth, 1981.

MERLEAU-PONTY, Maurice. O visível e o invisivel. São Paulo: Perspectiva, 1971.

RICOEUR, Paul. Métaphore vive. Paris : Seuil, 1975.

RICOEUR, Paul. Temps et Récit I. Paris : Seuil, 1983.

RICOEUR, Paul. Do texto à acção: ensaios de hermenêutica II. Porto: Rés Ed, 1986.

RICOEUR, Paul. O si-mesmo como um outro. Brasil, Papirus, 1990.

RICOEUR, Paul. Lectures I Autour du Politique. Paris : Seuil, 1991.

VYGOTSKY, Lev S. Thought and Language. Cambridge MA: Mit Press, 1987.

VYGOTSKY, Lev S. Psicologia pedagógica. Edição comentada. Porto Alegre: ARTMED, 2003.

VYGOTSKY, Lev S. A imaginação e a arte na infância. Lisboa: Relógio D`Àgua, 2009.

WUNEMBURGER, Jean J. A razão contraditória. Viseu: Instituto Piaget,1999. 